
\title{
25 Research Soure \\ Photocatalytic and Photoluminescence Studies of La, Ce and Dy Co-Doped ZnO Nanoflowers
}

\section{Syed Irtiqa}

National Institute of Technology Srinagar

Atikur Rahman ( $\nabla$ atikurrhmn@nitsri.net )

National Institute of Technology Srinagar

\section{Research Article}

Keywords: ZnO, La, Ce, Dy, co-doping, co-precipitation, photoluminescence, photocatalyst, rhodamine B, rare earths

Posted Date: February 26th, 2021

DOI: https://doi.org/10.21203/rs.3.rs-237092/v1

License: (c) (i) This work is licensed under a Creative Commons Attribution 4.0 International License. Read Full License

Version of Record: A version of this preprint was published at Journal of The Institution of Engineers (India): Series E on January 4th, 2022. See the published version at https://doi.org/10.1007/s40034-02100233-1. 


\title{
Photocatalytic and photoluminescence studies of La, Ce and Dy co-doped ZnO nanoflowers
}

Syed Irtiqa and Atikur Rahman*

Department of Metallurgical and Materials Engineering, National Institute of Technology Srinagar, Hazratbal, Srinagar-190006, India

*Corresponding author: atikurrhmn@gmail.com, atikurrhmn@ nitsri.net

Ph. no.: 0091-194-2429429

Fax: 0091-194-2420475

\begin{abstract}
In the present work, $\mathrm{ZnO}$ nanoparticles were doped with varying concentration of Lanthanum (La), Cerium (Ce) and Dysprosium (Dy) using a simple and cost effective co-precipitation approach at low temperatures. The resulting powders were calcined at $500{ }^{\circ} \mathrm{C}$ for 1 hour using a muffle furnace, to produce $\mathrm{La}, \mathrm{Ce}$, Dy co-doped $\mathrm{ZnO}$ nanoparticles with varying stoichiometry viz. $\quad \mathrm{Zn}_{0.97} \mathrm{La}_{0.01} \mathrm{Ce}_{0.01} \mathrm{Dy}_{0.01} \mathrm{O}, \quad \mathrm{Zn}_{0.94} \mathrm{La}_{0.02} \mathrm{Ce}_{0.02} \mathrm{Dy}_{0.02} \mathrm{O}, \quad \mathrm{Zn}_{0.91} \mathrm{La}_{0.03} \mathrm{Ce}_{0.03} \mathrm{Dy}_{0.03} \mathrm{O}$, $\mathrm{Zn}_{0.88} \mathrm{La}_{0.04} \mathrm{Ce}_{0.04} \mathrm{Dy}_{0.04} \mathrm{O}$ and $\mathrm{Zn}_{0.85} \mathrm{La}_{0.05} \mathrm{Ce}_{0.05} \mathrm{Dy}_{0.05} \mathrm{O}$. This is a simple approach for doping and doesn't require and complex equipment, harmful chemical or sophisticated machinery. The synthesized powders were characterized using X-Ray diffraction (XRD) and Scanning electron microscopy (SEM) for studying the structure, purity, and grain morphology. The average particle size was calculated using XRD and was found to be $35 \mathrm{~nm}$, it also indicated a hexagonal wurtizite structure with no secondary peaks. A change in morphology from nanorods to nanoflowers was observed as the concentration of dopants increased. Photoluminescence (PL) spectra indicated a red shift in the absorption edge towards the visible region of solar spectrum
\end{abstract}


and this was further confirmed by Diffuse Reflectance Spectra (DRS). The photocatalytic properties of undoped and $\mathrm{La}, \mathrm{Ce}, \mathrm{Dy}$ co-doped $\mathrm{ZnO}$ nanoparticles were observed by examining the photodegradation of Rhodamine B dye under UV irradiation. Elimination of dye color indicated the total degradation of organic molecule. The results revealed that $\mathrm{ZnO}$ photocatalyst with La, Ce, Dy co-doping concentration $\mathrm{Zn}_{0.85} \mathrm{La}_{0.05} \mathrm{Ce}_{0.05} \mathrm{Dy}_{0.05} \mathrm{O}$ exhibited the best photocatalytic performance $(95 \%)$ as compared to undoped $\mathrm{ZnO}$. The improved photocatalytic performance can be attributed to the increased surface oxygen vacancies and adsorption capacity. Delay in recombination of charge carriers due to creation trap states in the bandgap of $\mathrm{ZnO}$ further improves the photocatalytic performance of doped samples.

Keywords: $\mathrm{ZnO}$; La, Ce, Dy, co-doping; co-precipitation; photoluminescence; photocatalyst; rhodamine $\mathrm{B}$; rare earths

\section{Introduction.}

In present times the advancement in electronics and technology can be credited to the semiconductor nanomaterials. Amongst the semiconductor nanomaterials, $\mathrm{TiO}_{2}, \mathrm{ZnS}, \mathrm{ZnSe}$, $\mathrm{ZnO}, \mathrm{CdSe}$, indium tin oxide (ITO) etc exhibit excellent optical properties [1]. ZnO being a class II-VI semiconductor, has a wide bandgap (3.37 eV), high binding energy at room temperature, better chemical stability and very high melting point $\left(1975^{\circ} \mathrm{C}\right)$. Owing to it unique properties $\mathrm{ZnO}$ is the most commonly used semiconductor in optoelectronic applications viz. photocatalysis, photoluminescence, solar cells, field emission displays etc. Wide scale use of $\mathrm{ZnO}$ can be further attributed to its low cost, simple synthesis, little toxicity, electron transport capability and less crystallization temperature [2-7]. 
Doping i.e. incorporation of small quantity of impurity ions into the host lattice can tune and modify the properties of semiconductors to suit particular applications [8-12]. Optoelectronic and magnetic properties of $\mathrm{ZnO}$ can be easily modulated by doping. Among the materials used for doping, rare earth ions with $4 f$ configuration have gained maximum attention due to their unique luminescence and recombination sites for the electron hole pairs [13].

Semiconductors used as photocatalysts such as $\mathrm{ZnO}$ are crucial in easing the global concerns regarding waste water treatment. Water pollution and the scarcity of water induced by it are the major concerns of the scientific world today. Textile industry and dye production/ utilization units are the major contributors towards the water pollution. Large amounts of effluent water containing intense colored toxic dyes are produced by these every day. Rhodamine B dye owing to its high stability and low cost is the most commonly used dye in the textile industry and dye production units. However it is carcinogenic and mutagenic in nature and hence extremely harmful for human and aquatic life. So degradation of Rhodamine B dye is pivotal in waste water treatment, conservation of aquatic life and human safety [14]. Photocatalysis has evolved as an efficient, cost effective and environment friendly method for waste water treatment. Semiconductor nanomaterials like $\mathrm{TiO}_{2}, \mathrm{ZnS}, \mathrm{ZnO}$ are suitable candidates for photocatalysis, however $\mathrm{ZnO}$ is the most commonly used owing to its low cost, inertness to chemicals, nontoxicity and resistance against corrosion [15-19]. In practical applications however, $\mathrm{ZnO}$ has narrow range of spectral response especially under UV irradiation $(\lambda<380 \mathrm{~nm})$ which contributes to only $6-8 \%$ of solar energy whereas visible light contributes $46 \%$. Further, due to less separation between the photo-generated charge carriers, recombination and dissipation of energy takes place in nanoseconds, making it difficult to utilize the photo-generated electrons and holes. These electrons and holes act as powerful oxidizing and reducing agents respectively 
and a delayed recombination can make them suitable for redox reactions, which leads to better photocatalysis [20, 21]. Hence to obtain a better photocatalyst out of $\mathrm{ZnO}$, its absorption edge needs to be shifted towards the visible region and photogenerated electrons and holes need to have a better charge separation. These requirements can be achieved by doping rare earth ions into the $\mathrm{ZnO}$ matrix [22-26]. Monovalent doping of lanthanides viz. lanthanum (La), cerium (Ce), dysprosium (Dy) has been extensively studied [27-31]. Amongst these monovalent rare earth dopants, cerium is distinctly interesting due to its large ionic radius, which causes a localized charge perturbance when substituted into the lattice of $\mathrm{ZnO}$ and hence leads to better photocatalysis [32-36]. Few precedents of divalent dopings are available in the literature, showing such doping leads to much better and improved photocatalysis and bandgap tailoring [37-43]. There are no studies on trivalent doping of $\mathrm{ZnO}$ in literature. This motivated us to do a detailed analysis of Lanthanum, Cerium and dysprosium co-doping into $\mathrm{ZnO}$ matrix and we observed much improved optical properties. The improvement was observed on multiple fronts. We hereby report a facile and cost effective synthesis of $\mathrm{La}, \mathrm{Ce}$, Dy co-doped $\mathrm{ZnO}$ nanoparticles with improved and optimized photocatalytic activities, a better dopant dependent bandap, red shift in the absorption edge and much improved charge separation between the photogenerated charge carriers. Better charge separation is a consequence of dopant induced trap levels in the bandgap of $\mathrm{ZnO}$.

Several methods have been utilized so far for the synthesis of rare earth doped $\mathrm{ZnO}$ nanoparticles which include forced hydrolysis [44], pulsed laser deposition [45] and combustion methods [46]. All these methods are quite complex and require costly machinery, high temperatures and toxic chemicals. 
In the present work, we report a facile, cost effective and environmental friendly coprecipitation technique for synthesizing $\mathrm{La}, \mathrm{Ce}$, Dy co-doped $\mathrm{ZnO}$ nanoparticles with varying stoichiometry viz. $\mathrm{Zn}_{0.97} \mathrm{La}_{0.01} \mathrm{Ce}_{0.01} \mathrm{Dy}_{0.01} \mathrm{O}, \mathrm{Zn}_{0 .{ }_{9} 4 \mathrm{La} 0.02} \mathrm{Ce}_{0.02} \mathrm{Dy}_{0.02} \mathrm{O}, \mathrm{Zn}_{0.91} \mathrm{La}_{0.03} \mathrm{Ce}_{0.03} \mathrm{Dy}_{0.03} \mathrm{O}$, $\mathrm{Zn}_{0.88} \mathrm{La}_{0.04} \mathrm{Ce}_{0.04} \mathrm{Dy}_{0.04} \mathrm{O}$ and $\mathrm{Zn}_{0.85} \mathrm{La}_{0.05} \mathrm{Ce}_{0.05} \mathrm{Dy}_{0.05} \mathrm{O}$. Optical properties of all dopant concentrations were compared. Structural, morphological, photoluminescence and bandgap studies were done using XRD, SEM, PL and DRS respectively. Photocatalytic properties of undoped La, Ce, Dy doped $\mathrm{ZnO}$ nanoparticles were analyzed by observing the decomposition of Rhodamine B under UV light irradiation. The degradation of harmful dye and ensuing removal of color was much improved in La, Ce, Dy co-doped samples as compared to the undoped $\mathrm{ZnO}$. The detailed mechanism of photocatalytic degradation of Rhodamine B dye is discussed in the present work.

\section{Experimental Procedure.}

A low cost, facile an environment friendly co-precipitation approach was utilized for synthesizing $\mathrm{La}, \mathrm{Ce}, \quad \mathrm{Dy}$ co-doped $\mathrm{ZnO}$ nanoparticles $\left(\mathrm{Zn}_{0.97} \mathrm{La}_{0.01} \mathrm{Ce}_{0.01} \mathrm{Dy}_{0.01} \mathrm{O}\right.$, $\mathrm{Zn}_{0.94} \mathrm{La}_{0.02} \mathrm{Ce}_{0.02} \mathrm{Dy}_{0.02} \mathrm{O}, \quad \mathrm{Zn}_{0.91} \mathrm{La}_{0.03} \mathrm{Ce}_{0.03} \mathrm{Dy}_{0.03} \mathrm{O}, \quad \mathrm{Zn}_{0.88} \mathrm{Laa}_{0.04} \mathrm{Ce}_{0.04} \mathrm{Dy}_{0.04} \mathrm{O} \quad$ and $\mathrm{Zn}_{0.85} \mathrm{La}_{0.05} \mathrm{Ce}_{0.05} \mathrm{Dy}_{0.05} \mathrm{O}$ ). The mole fraction of the constituent ions was maintained by controlling the weight ratio of dopants $\mathrm{La}, \mathrm{Ce}$ and Dy to host $\mathrm{Zn}$. The starting material and the dopant sources used viz. zinc acetate dihydrate $\left[\mathrm{Zn}\left(\mathrm{COOCH}_{3}\right)_{2} 2\left(\mathrm{H}_{2} \mathrm{O}\right)\right]$, lanthanum(III)acetate sesquihydrate $\left[\mathrm{La}\left(\mathrm{CH}_{3} \mathrm{COO}\right)_{3} 1.5\left(\mathrm{H}_{2} \mathrm{O}\right)\right]$, Cerium(III)acetate tetrahydrate $\left.\left[\mathrm{Ce}\left(\mathrm{CH}_{3} \mathrm{COO}\right)_{3} 4 \mathrm{H}_{2} \mathrm{O}\right)\right]$ and dysprosium(III)acetate tetrahydrate $\left.\left[\mathrm{Dy}\left(\mathrm{CH}_{3} \mathrm{COO}\right)_{3} 4 \mathrm{H}_{2} \mathrm{O}\right)\right]$, were of high purity (Sigma Aldrich 99\% purity) and were used as such without any further purification. Distilled water was used as the reaction medium and diethylamine as the reducing as well as stabilizing agent. To begin with, undoped $\mathrm{ZnO}$ nanoparticles were synthesized by taking $0.5 \mathrm{M}$ zinc acetate solution 
in a beaker at $60{ }^{\circ} \mathrm{C}$ and adding $5 \mathrm{ml}$ of diethylamine slowly to it. The solution was stirred at 60 ${ }^{\circ} \mathrm{C}$ for 30 mins followed by heating at $180{ }^{\circ} \mathrm{C}$. The resulting powders were obtained by centrifugation and were annealed at $500{ }^{\circ} \mathrm{C}$ in a muffle furnace for 1 hour.

In order to obtain the $\mathrm{La}, \mathrm{Ce}$, Dy co-doped samples i.e. $\mathrm{Zn}_{0.97} \mathrm{La}_{0.01} \mathrm{Ce}_{0.01} \mathrm{Dy}_{0.01} \mathrm{O}$, $\mathrm{Zn}_{0.94} \mathrm{La}_{0.02} \mathrm{Ce}_{0.02} \mathrm{Dy}_{0.02} \mathrm{O}, \quad \mathrm{Zn}_{0.91} \mathrm{La}_{0.03} \mathrm{Ce}_{0.03} \mathrm{Dy}_{0.03} \mathrm{O}, \quad \mathrm{Zn}_{0.88} \mathrm{La}_{0.04} \mathrm{Ce}_{0.04} \mathrm{Dy}_{0.04} \mathrm{O} \quad$ and $\mathrm{Zn}_{0.85} \mathrm{La}_{0.05} \mathrm{Ce}_{0.05} \mathrm{Dy}_{0.05} \mathrm{O}$, the dopant ion salts were used to prepare their solutions in distilled water with concentrations varying from $0.01 \mathrm{M}$ to $0.05 \mathrm{M}$. These solutions were then added to $0.5 \mathrm{M} \mathrm{ZnO}$ solution under stirring at $60{ }^{\circ} \mathrm{C} .5 \mathrm{ml}$ of diethylamine was added to this solution dropwise. The heating was further continued for 1 hour and the resulting powders were centrifuged and cleaned with ethanol and annealed at $500{ }^{\circ} \mathrm{C}$ for each molar concentration from $0.01 \mathrm{M}$ to $0.05 \mathrm{M}$. The standard conditions and molarities for the synthesis of $\mathrm{La}, \mathrm{Ce}$, Dy codoped $\mathrm{ZnO}$ nanoparticles are depicted in table 1.

The structural properties of nanoparticles were examined using X- Ray diffractometer with $\mathrm{CuK} \alpha \operatorname{target}(\mathrm{k}=1.54052 \AA)$. The radiation was over the range of $2 \theta$ from $10-90^{\circ}$ and step was 0.01. The morphological features of undoped $\mathrm{ZnO}$ and $\mathrm{La}, \mathrm{Ce}$, Dy co-doped $\mathrm{ZnO}$ nanoparticles was observed under SEM. Horiba LabRam spectrometer with an excitation source of $325 \mathrm{~nm}$ (wavelength) and an accumulation time of 2 seconds was used to record the PL spectrum of the undoped and doped $\mathrm{ZnO}$ nanoparticles. Optical studies were done using DRS, UV-Vis,- NIR spectrometer at a normal incidence of powder samples (USB 2000 and deuterium halogen power source DH-2000 Micropack; Ocean Optics).

\subsection{Photocatalytic Activity measurement.}


To measure the photocatalytic activity of undoped and $\mathrm{La}$, Ce, Dy co-doped $\mathrm{ZnO}$ nanoparticles, $40 \mathrm{mg}$ of nanoparticle powder was weighed. In a $250 \mathrm{ml}$ beaker $10 \mathrm{ml}$ of $10 \mathrm{ppm}$ Rhodamine B dye solution was taken and to this $30 \mathrm{ml}$ of distilled water was added. Finally the weighed nanoparticle powder was added to this dye solution. This solution was wrapped, kept in dark and stirred for half an hour to disperse the photocatalyst nanoparticles and establish adsorptiondesorption equilibrium. Afterwards the solution was irradiated with UV light in the photocatalytic reactor (M/S Technistro, Nagpur, Maharashtra) fitted with high pressure mercury lamp with capacity $450 \mathrm{~W}$ (operating voltage, 110-220 V), whilst the stirring was continued. A 3 $\mathrm{ml}$ aliquot was taken at an interval of 10 mins and immediately centrifuged to remove nanocatalyst. Absorbance of the samples was measured using UV-Vis spectrometer (Perkin Elmer lambda 35) run between 400-600 nm. A decrease in absorbance and removal of dye color confirmed the degradation of Rhodamine B dye with undoped and $\mathrm{La}, \mathrm{Ce}$, Dy co-doped $\mathrm{ZnO}$ as photocatalyst.

\section{Results and Discussion}

\subsection{Structural Analysis.}

Fig.1 (a) reveals the XRD pattern of undoped and $\mathrm{La}, \mathrm{Ce}$, Dy co-doped $\mathrm{ZnO}$ nanoparticles with concentrations $\quad\left(\mathrm{Zn}_{0.97} \mathrm{La}_{0.01} \mathrm{Ce}_{0.01} \mathrm{Dy}_{0.01} \mathrm{O}, \quad \mathrm{Zn}_{0 .{ }^{2} 4} \mathrm{La}_{0.02} \mathrm{Ce}_{0.02} \mathrm{Dy}_{0.02} \mathrm{O}, \quad \mathrm{Zn}_{0.91} \mathrm{La}_{0.03} \mathrm{Ce}_{0.03} \mathrm{Dy}_{0.03} \mathrm{O}\right.$, $\mathrm{Zn}_{0.88} \mathrm{Laa}_{0.04} \mathrm{Ce}_{0.04} \mathrm{Dy}_{0.04} \mathrm{O}$ and $\left.\mathrm{Zn}_{0.85} \mathrm{La}_{0.05} \mathrm{Ce}_{0.05} \mathrm{Dy}_{0.05} \mathrm{O}\right) \mathrm{ZnO}$ nanoparticles $\mathrm{XRD}$ analysis shows all the nanoparticles formed are of hexagonal wurtzite phase as per the The International Centre for Diffraction Data (ICDD) database number 01-070-8072. The broadness of all the peaks indicated purely crystalline nature of the nanoparticles. Further analysis revealed there were no secondary peaks other than $\mathrm{ZnO}$ indicating all the samples formed were pure phase. The ionic radius of host ion $\mathrm{Zn}^{2+}(0.72 \AA)$ is small as compared to the dopant ions i.e. $\mathrm{La}^{3+}(1.06 \AA), \mathrm{Ce}^{3+}$ 
$(1.03 \AA)$ and $\mathrm{Dy}^{3+}(0.91 \AA$ ) which leads to distortion in the $\mathrm{ZnO}$ lattice and also there is a shift towards lower angle in the doped samples, confirming substitutional doping of La, Ce, Dy codopants in $\mathrm{ZnO}$ matrix which is shown in Fig. 1(b). The formulae used for the calculation of lattice parameters and crystallite size respectively are listed below and the numeric values of same are given in table 2. Mismatch of ionic radii of host $\mathrm{Zn}^{2+}$ ion and dopant ions leads to an increase in bond length which gets reflected in increased values of lattice constants $a$ and $c$ as shown in table 2.

$$
\begin{aligned}
& a=\frac{\lambda}{\sqrt[3]{\sin \theta}} \\
& b=\frac{\lambda}{\sin \theta} \\
& D=\frac{K \lambda}{\beta \cos \theta}
\end{aligned}
$$

In the above formulae $\lambda$ represents the wavelength of target used in the X-ray diffractometer used and its value is $1.5406 \AA$ Á. $\theta$ and $\mathrm{K}$ represent the diffraction angle and the shape factor respectively, $\mathrm{D}$ is crystallite size and $\beta$ denotes full width half maximum. The crystallite size decreases from $47 \mathrm{~nm}$ in case of undoped $\mathrm{ZnO}$ to around $35 \mathrm{~nm}$ in case of doped nanoparticles, hence dopant concentration restricts the growth of nanoparticles in doped samples and which was confirmed and explained using scanning electron microscopy SEM.

\subsection{Morphological Studies.}

The SEM micrographs of undoped and La, Ce, Dy co-doped $\mathrm{ZnO}$ with concentrations $\mathrm{Zn}_{0.97} \mathrm{La}_{0.01} \mathrm{Ce}_{0.01} \mathrm{Dy}_{0.01} \mathrm{O}, \quad \mathrm{Zn}_{0.94} \mathrm{La}_{0.02} \mathrm{Ce}_{0.02} \mathrm{Dy}_{0.02} \mathrm{O}, \quad \mathrm{Zn}_{0.91} \mathrm{La}_{0.03} \mathrm{Ce}_{0.03} \mathrm{Dy}_{0.03} \mathrm{O}$, $\mathrm{Zn}_{0.88} \mathrm{La}_{0.04} \mathrm{Ce}_{0.04} \mathrm{Dy}_{0.04} \mathrm{O}$ and $\mathrm{Zn}_{0.85} \mathrm{Laa}_{0.05} \mathrm{Ce}_{0.05} \mathrm{Dy}_{0.05} \mathrm{O}$, are shown in Fig.2 (a-e). It can be clearly seen from the SEM micrographs that the SEM results are in concurrence with the XRD results. Increase in dopant concentration leads to decrease in particle size. Ionic radii of dopant ions $\mathrm{La}^{3+}$ 
(1.06 $\AA), \mathrm{Ce}^{3+}(1.03 \AA)$ and $\mathrm{Dy}^{3+}\left(0.91 \AA\right.$ ) are quite large as compared to the host $\mathrm{Zn}^{2+}$ ion i.e. $(0.72 \AA ̊)$. This mismatch in ionic radii leads to lattice strain and eventually a decreased grain size in case of doped nanoparticles. It can be observed from the SEM micrographs that on increasing the dopant concentration the morphology of the nanoparticles eventually becomes flower like. This phenomenon can be credited to the $\mathrm{Ce}^{3+}$ ion doping which plays a pivotal role in capping the nanoparticles formed after nucleation [47]. The $\mathrm{Ce}^{3+}$ ions cause steric hindrances in presence of a strongly absorbed reducing agent- diethylamine, which leads to formation of flower like structure in case of $\mathrm{La}, \mathrm{Ce}$, Dy co-doped $\mathrm{ZnO}$ nanoparticles. This can be further explained with the help of growth and nucleation of nanoparticles. A precursor initiates the formation of seed nuclei which then grow to form rods by Ostwald ripening effect, in which larger particles grow at the expense of smaller particles. Solvent facilitates this process and various subunits formed are connected by the orientation attachment process leading to flower like morphology [48].

\subsection{Photoluminescence Studies.}

Important properties of semiconductors like bandgap, energy levels, chemical composition and type of impurity can be extensively studied with the help of photoluminescence (PL). The PL spectra of undoped and $\mathrm{La}, \mathrm{Ce}$, Dy co-doped $\mathrm{ZnO}$ nanoparticles are shown in Fig. 3(a). The spectra were obtained by exciting the sample at a wavelength of $325 \mathrm{~nm}$. The PL spectrum of pure or undoped $\mathrm{ZnO}$ depicts two prominent emission peaks at $390 \mathrm{~nm}$ and $710 \mathrm{~nm}$. The first prominent peak at $390 \mathrm{~nm}$ corresponds to the UV region and can be due to near band edge emission caused by the recombination of free and bound exciton pairs. The second peak at 710 $\mathrm{nm}$ corresponds to the near infrared region and is possibly ascribed to surface plasma resonance [49]. It is clear from Fig.3 (a) La, Ce, Dy co-doping has two important influences on the 
photoluminescence emission peaks in UV region that is decrease in intensity of emission peaks and shifting of emission peaks towards the higher wavelength. Decrease in intensity can be attributed to the transfer of energy from host $\mathrm{ZnO}$ to dopants $\mathrm{La}, \mathrm{Ce}$ and $\mathrm{Dy}$ which confirms perfect substitution of dopants into the host matrix. Decrease in peak intensity and consequent decrease in energy also indicates delayed recombination with increase in dopant concentration. This pertains to the fact that increased dopant concentration leads to surface bound states acting as trap states resulting in non radiative relaxation. The PL intensity depends on the distance between these trap states and their centre to centre interaction. The spectral overlap between the wave functions of these states leads to dissipation of energy in non-radiative manner and consequent decrease in energy [50]. La, Ce, Dy co-doping also leads to shifting of the peak in UV region towards the visible region of spectrum as can be seen in Fig. 3(b). This is a very important consequence which can lead to better utilization of the solar energy and pave way for excellent optoelectronic applications. This red shift can be attributed to creation of electronic states near the conduction band of $\mathrm{ZnO}$ due to presence of dopants, which also leads to narrowing of bandgap of $\mathrm{ZnO}$ as has already been reported in Ce-doped nitrides [51]. Narrowing of bandgap can further be credited to the narrow optical transitions within spin orbital levels due to tailoring of conduction and valence bands caused by dopant induced potential fluctuations [52]. As the electronegativities of the dopant ions $\mathrm{La}^{3+}(1.1), \mathrm{Dy}^{3+}(1.22)$ and $\mathrm{Ce}^{3+}(1.12)$ are less than the electronegativity of host $\mathrm{Zn}^{2+}(1.65)$, the columbic interaction between electrons-holes pairs bound by isoelectronic levels formed by $\mathrm{La}, \mathrm{Ce}$ and Dy generates acceptor bound excitation pair. This leads to charge transfer between conduction band of $\mathrm{ZnO}$ and different states of dopants, effecting a red shift which consequently narrows the bandgap.

\subsection{Photocatalytic studies.}


The photocatalytic activities of undoped and $\mathrm{La}, \mathrm{Ce}$, Dy co-doped $\mathrm{ZnO}$ nanoparticles were evaluated by observing the degradation of Rhodamine B dye under UV light irradiation and using these nanoparticles as photocatalysts. Fig. 4 (a-f) reveals the degradation of Rhodamine B dye with $\mathrm{ZnO}$ and $\mathrm{La}, \mathrm{Ce}$, Dy co-doped $\mathrm{ZnO}$ as nano photocatalysts within reaction times from 0-60 min. Degradation is confirmed as the absorbance of dye decreases with increase in concentration of dopants and reaction time. We observed the fastest and most efficient degradation with $\mathrm{Zn}_{0.85} \mathrm{La} 0.05 \mathrm{Ce}_{0.05} \mathrm{Dy}_{0.05} \mathrm{O}$ nanoparticles as photocatalyst. The photocatalytic performance of undoped and $\mathrm{La}, \mathrm{Ce}$, Dy co- doped $\mathrm{ZnO}$ nanaoprticles was evaluated by taking the plot between $\mathrm{Ct} / \mathrm{Co}$ and irradiation time (t), where Co is the initial dye concentration and $\mathrm{Ct}$ is the residual dye concentration after a time interval $t$ as shown in Fig. 5(a). Degradation of Rhodamine B dye roughly obeys pseudo first order kinetics for low concentration of dyes [54].

$$
\ln \left[C_{t} / C_{o}\right]=K * t
$$

Where $\mathrm{K}$ represents the constant-kinetic parameter and is different for different photocatalysts. The value of constant $\mathrm{K}$ can be found by linear fitting the slope of graph obtained between $\mathrm{ln}$ $\left(\mathrm{C}_{\mathrm{t}} / \mathrm{C}_{\mathrm{o}}\right)$ and irradiation time $t$ as is shown in Fig.5 (b). The values of $\mathrm{K}$ obtained in this case were $0.0247 \mathrm{~S}^{-1}, 0.0408 \mathrm{~S}^{-1}, 0.0407 \mathrm{~S}^{-1}, 0.055 \mathrm{~S}^{-1}, 0.058 \mathrm{~S}^{-1}$ and $0.060 \mathrm{~S}^{-1}$ for undoped and La, Ce, Dy co-doped $\quad \mathrm{ZnO} \quad$ nanoparticles $\quad\left(\mathrm{Zn}_{0.97} \mathrm{La}_{0.01} \mathrm{Ce}_{0.01} \mathrm{Dy}_{0.01} \mathrm{O}, \quad \mathrm{Zn}_{0.94} \mathrm{La}_{0.02} \mathrm{Ce}_{0.02} \mathrm{Dy}_{0.02} \mathrm{O}\right.$, $\mathrm{Zn}_{0.91} \mathrm{La}_{0.03} \mathrm{Ce}_{0.03} \mathrm{Dy}_{0.03} \mathrm{O}, \mathrm{Zn}_{0.88} \mathrm{La}_{0.04} \mathrm{Ce}_{0.04} \mathrm{Dy}_{0.04} \mathrm{O}$ and $\left.\mathrm{Zn}_{0.85} \mathrm{La}_{0.05} \mathrm{Ce}_{0.05} \mathrm{Dy}_{0.05} \mathrm{O}\right)$ respectively. The value of $\mathrm{K}$ was found to be highest in case of highest doping concentration i.e. $\mathrm{Zn}_{0.85} \mathrm{La}_{0.05} \mathrm{Ce}_{0.05} \mathrm{Dy}_{0.05} \mathrm{O}$. The degradation efficiency was further studies by calculating the degradation percentage using the formula given below.

$$
\% D=\left(1-C_{t} / C_{o}\right) * 100
$$


Where $\% D$ is the degradation percentage, $C_{o}$ is the initial concentration of dye and $\mathrm{C} t$ is the concentration of dye after interval $t$. Degradation percentage was found to be highest (93\%) for $\mathrm{Zn}_{0.85} \mathrm{La}_{0.05} \mathrm{Ce}_{0.05} \mathrm{Dy}_{0.05} \mathrm{O}$ nanoparticles as photocatalyst. This is depicted graphically in Fig. 5(c). Enhanced photocatalytic activity of $\mathrm{ZnO}$ nanoparticles with trivalent rare earth doping can be explained by investigating the degradation mechanism of Rhodamine B dye as follows. The semiconductor nanoparticles to be investigated as photocatalysts are initially excited with photons having energy greater than the bandgap i.e. (hv > bandgap). This excitation generates electron hole pairs on the surface of the nanoparticle. These photo-generated electron hole pairs are trapped by oxygen $\left(\mathrm{O}_{2}\right)$, which is adsorbed on the surface of the nanoparticle. This trapping of photo-generated electrons and holes is the rate determining step in photocatalyis reaction. The $4 f$ configuration of rare earth dopants also plays a pivotal role in generation, delayed recombination and delayed charge transfer of electron hole pairs. $\mathrm{La}^{4+}, \mathrm{Ce}^{4+}$ and $\mathrm{Dy}^{4+}$ act as scavenger for the electron from conduction band as these are stronger Lewis acids compared to $\mathrm{O}_{2}$ and hence better at trapping the electrons and holes. The electrons trapped by the dopants are transferred oxidatively to the surface adsorbed oxygen to produce the superoxide radical $\left(* \mathrm{O}_{2}{ }^{-}\right)$. The electrons and holes generated by high energy photons can easily recombine and dissipate the energy, which prevents their efficient utilization. The recombination of photo-generated electrons and holes can be prevented in the presence of defect states. In the present work, singly oxygen vacancies $\left(\mathrm{Vo}^{+}\right)$act as trap states to enhance the separation between photo-generated electrons and holes. The singly oxygen vacancy acts as electron donor to become charged oxygen vacancy which then acts as trap for photo-generated holes and prevents recombination. This charged oxygen vacancy on reaction with the hydroxyl ion $\left(\mathrm{OH}^{-}\right)$forms hydroxyl radical $\left(\mathrm{OH}^{*}\right)$. This can be summarized as, 
Incident photons $+\mathrm{ZnO} \rightarrow$ electrons $\left(\mathrm{e}^{-}\right)+$holes $\left(\mathrm{h}^{+}\right)$

$\mathrm{Ce}^{4+}+\mathrm{e}^{-} \rightarrow \mathrm{Ce}^{3+}$

$\mathrm{Dy}^{4+}+\mathrm{e}^{-} \rightarrow \mathrm{Dy}^{3+}$

$\mathrm{e}^{-}+\mathrm{O}^{2} \rightarrow{ }^{*} \mathrm{O}_{2}^{-} \quad$ (superoxide)

$\mathrm{Vo}^{+}+\mathrm{h}^{+} \rightarrow \mathrm{Vo}^{2+}$

$\mathrm{V}_{\mathrm{o}}^{2+}+\mathrm{OH}^{-} \rightarrow \mathrm{Vo}^{+}+* \mathrm{OH}$ (hydroxyl radical)

$* \mathrm{O}_{2}{ }^{-}+2 \mathrm{H}^{+} \rightarrow 2(* \mathrm{OH})$

Organic pollutant $+\mathrm{OH}^{*}+\mathrm{O}_{2} \rightarrow \mathrm{CO}_{2}+\mathrm{H}_{2} \mathrm{O}+$ degraded products

Oxygen vacancies don't only trap holes, they also help in adsorbing oxygen and hence further enhance photocatalysis [55].

The efficiency of any photocatalyst depends on a number of factors which include number of charge carriers on the surface, and recombination rate of the electron hole pairs generated upon incidence of high energy photon. In the present work, rare earth doping in $\mathrm{ZnO}$ has been utilized to increase its photocatalytic activity many folds as compared to the undoped $\mathrm{ZnO}$. The reason for this can be credited to loading of charge carriers on the surface as a consequence of decrease in size and increase in surface area on doping and presence of oxygen vacancies in the bandgap of $\mathrm{ZnO}$ due to trivalent rare earth doping. Photoluminescence (PL) studies Fig. 3 (a-b) reveal that the trivalent rare earth doping causes the shifting of absorption edge towards the visible region and narrowing of bandgap. Both these effects can lead to better utilization of solar energy and hence more efficient photocatalysis. Further PL spectrum reveals incorporation of additional levels in the bandgap of $\mathrm{ZnO}$ upon rare earth doping which further delays the recombination of charge carriers leading to efficient photocatalysis. This red shift in absorption edge and bandgap narrowing are also confirmed by diffuse reflectance studies (DRS). 


\subsection{Optical Studies, Diffuse Reflectance Studies-(DRS).}

Fig.6 (a) depicts the diffuse reflectance spectra of undoped and $\mathrm{La}, \mathrm{Ce}$, Dy co-doped $\mathrm{ZnO}$ nanoparticles of following concentrations $\left(\mathrm{Zn}_{0.97} \mathrm{La}_{0.01} \mathrm{Ce}_{0.01} \mathrm{Dy}_{0.01} \mathrm{O}, \mathrm{Zn}_{0.91} \mathrm{La}_{0.03} \mathrm{Ce}_{0.03} \mathrm{Dy}_{0.03} \mathrm{O}\right.$, and $\mathrm{Zn}_{0.85} \mathrm{La}_{0.05} \mathrm{Ce}_{0.05} \mathrm{Dy}_{0.05} \mathrm{O}$ ). All the samples showed high reflection in visible region, confirming a small absorption of visible light by all samples. Co-doping was seen to enhance the percentage of visible light reflectance, which has also been reported previously [56, 57]. The bandgap was calculated from the reflectance using the Kubela-Munk function:

$$
F(R)=(1-R)^{2} / 2 R
$$

Where $F(R)$ the Kubela-Munk is function and $R$ represents the reflectance [58, 59], $R$ is found from the $y$ axis of the plot between reflectance and wavelength Fig. 6 (a). $F(R)$ is calculated using the above formula and then a plot is drawn between $[F(R) h v]^{2} v s h v$. Here $h$ is the Plank's constant and $v$ is the frequency, $v=1 / \lambda$ and wavelength $\lambda$ is found from $x$-axis of graph shown in Fig. 6 (a). The lines in Fig. 6 (b) show the extrapolation of linear portion of plot $F(R) h v]^{2} v s h v$. The points at which these lines touch the $x$-axis give us the bandgap values. The bandgap of undoped $\mathrm{ZnO}$ was found to be $3.12 \mathrm{eV}$. For doped samples a decrease in bandgap was observed. Band gap values of $3.04 \mathrm{eV}, 3.0 \mathrm{eV}$ and $2.85 \mathrm{eV}$ were found for $\mathrm{Zn}_{0.97} \mathrm{La}_{0.01} C e_{0.01} \mathrm{Dy}_{0.01} \mathrm{O}, \quad \mathrm{Zn}_{0.91} \mathrm{La}_{0.03} \mathrm{Ce}_{0.03} \mathrm{Dy}_{0.03} \mathrm{O}, \quad$ and $\quad \mathrm{Zn}_{0.85} \mathrm{La}_{0.05} \mathrm{Ce}_{0.05} \mathrm{Dy}_{0.05} \mathrm{O}$ samples respectively. Red shift along with narrowing of bandgap can be attributed to the creation of additional trap or defect states in the bandgap of $\mathrm{ZnO}$ and formation of oxygen vacancies due to doping. These lead to increase in average atomic distance and hence decrease in bandgap.

\section{Conclusion.}

Pure and $\mathrm{La}, \mathrm{Ce}$, Dy co-doped $\mathrm{ZnO}$ nanoparticles were successfully prepared using a facile and cost effective approach of co-precipitation. Successful formation of nanoparticles was confirmed 
by XRD. A slight distortion in XRD pattern of doped samples was found due to ionic radii mismatch between host and dopant ions. Average particle size was found to be around $35 \mathrm{~nm}$. Morphology was evaluated using SEM, and the doped nanoparticles were found to have a flower like morphology. Photoluminescence PL studies revealed a red shift in absorption edge and narrowing of bandgap. Tunable band gap makes the doped nanoparticles excellent candidates for optoelectronic applications. Photocatalytic studies confirmed an enhanced and optimized photo catalytic performance in case of La, Ce, Dy co-doped samples due delayed recombination of photogenerated charge carriers, creation of additional levels in the band gap of $\mathrm{ZnO}$, increased surface oxygen vacancies and charge transfer. The sample, $\mathrm{Zn}_{0.85} \mathrm{La}_{0.05} \mathrm{Ce}_{0.05} \mathrm{Dy}_{0.05} \mathrm{O}$ exhibited the best photo-catalytic performance for the degradation of Rhodamine B dye.

\section{References:}

[1]. P. Thiyagarajan, M. Kottaisamy, K. Sethupathi and M. S. R. Rao, J. Displays, 30, 202, (2009).

[2]. C. Zhang and J. Lin, Chem. Soc. Rev., 41, 7938, (2012).

[3]. M. Shang, G. Li, D. Yang, X. Kang, C. Peng, Z. Cheng and J. Lin, Dalton Trans., 40, 9379, (2011).

[4]. P. V. Korake, R. S. Dhabbe, A. N. Kadam, Y. B. Gaikwad and K. M. Garadkar, J. Photochem. Photobiol. B, 130, 11, (2014).

[5]. Ü. Özgür, Y. I. Alivov, C. Liu, A. Teke, M. A. Reshchikov, S. Doğan, V. Avrutin, S. J. Cho and H. Morkoç, J. Appl. Phys., 98, 041301, (2005).

[6]. U. O. H. Morkoc, Zinc Oxide: Fundamentals, Materials and Device Technology, Wiley, (2009). 
[7]. S. Baskoutas and G. Bester, J. Phys. Chem. C, 114, 9301, (2010).

[8]. S. C. Erwin, L. Zu, M. I. Haftel, A. L. Efros, T. A. Kennedy and D. J. Norris, Nature,436, 91, (2005).

[9]. D. J. Norris, A. L. Efros and S. C. Erwin, Science, 319, 1776, (2008).

[10]. K. Yim, J. Lee, D. Lee, M. Lee, E. Cho, H. S. Lee, H.-H. Nahm and S. Han, Sci. Rep., 7, 40907, (2017).

[11]. T. Makino, Y. Segawa, S. Yoshida, A. Tsukazaki, A. Ohtomo and M. Kawasaki, Appl. Phys. Lett., 85, 759, (2008).

[12]. S. Singh, N. Rama and M. S. R. Rao, Appl. Phys. Lett., 88, 222111, (2006).

[13]. A. Azarov, A. Galeckas, A. Hallén, A. Kuznetsov, E. Monakhov and B. G. Svensson, J. Appl. Phy., 118, 125703, (2015).

[14]. A. Kunz, P. Peralta-Zamora, S. G. de Moraes, N. Duran, Quimica Nova, 25, 78, (2002).

[15]. P. V. Korake, A. N. Kadam, K. M. Garadkar, J. Rare Earths, 32, 306, (2014).

[16]. N. Shaari, S. H. Tan, A. R. Mohamed, J. Rare Earths, 30, 651, (2012.)

[17]. X. J. Yu, L. L. Xiong, G. P. Ma, Y. Liang, K. R. Liu., J. Rare Earths, 32,849, (2014).

[18]. C. Wang, L .Cao, J. Rare Earths, 29, 727, (2011).

[19]. J. Wu, G. L. Zhang, J. Liu, H. B. Gao, C. X. Song, H.R Du, Z. Li, Z.P Gong, Y.G Lu. J. Rare Earths, 32, 727, (2014).

[20]. A. L. Linsebigler, G. Q. Lu, J.T. Yates Jr., Chem. Rev., 95, 735, (1995). 
[21]. M. Romero, J. Blanco, B. Sanchez, A. Vidal, S. Malato, A. I. Cardona et. al., Sol. Energy, 66, 169, (1999).

[22]. M. Ahmad, E. Ahmed, Z. L. Hong, J. F Xu, N. R. Khalid, A. Elhissi, W. Ahmed, J. Alloys Compd., 577, 717, (2013).

[23]. M. Ahmad, E. Ahmed, Z. L. Hong, Z. Iqbal, N. R. Khalid, T. Abbas, I. Ahmad, A. Elhissi, W. Ahmed, Ceram. Int., 39, 8693, (2013).

[24]. M. Ahmad, E. Ahmed, Z. L. Hong, X. L. Jiao, T. Abbas, N. R. Khalid, Appl. Surf. Sci., 285P, 702, (2013).

[25]. H. S. Cai, G. G. Liu, W. Y. Lu, X. X. Li, L. Yu, D. G. Li, J. Rare Earths, 26, 71, (2008).

[26]. S. Kumar, P. D. Sahare, J. Rare Earths, 30, 761, (2012).

[27]. D. K. Sharma, K. K. Sharma, V. Kumar and A. Sharma, J. Mater. Sci.: Mater. Electron., 27, 10330, (2016).

[28]. Q. Shi, C. Wang, S. Li, Q. Wang, B. Zhang, W. Wang, J. Zhang and H. Zhu, Nanoscale Res. Lett., 9, 480, (2014).

[29]. M. Ahmad, E. Ahmed, F. Zafar, N. R. Khalid, N. A. Niaz, A. Hafeez, M. Ikram, M. A. Khan and Z. Hong, J. Rare Earths, 33, 255, (2015).

[30]. N. C. S. Selvam, J. J. Vijaya and L. J. Kennedy, J. Nanosci. Nanotechnol, 13, 1, (2013).

[31]. S. Rajendran, M. M. Khan, F. Gracia, J. Qin, V. K. Gupta and S. Arumainathan, Sci. Rep., 6, 31641, (2016).

[32]. H. X. Shi, T. Y. Zhang, H.L. Wang. J. Rare Earths, 29, 746, (2011).

[33]. R. Zeng, J. G. Wang, J. Y. Cui, L. Hu, K.G. Mu, J. Rare Earths, 28, 353, (2010).

[34]. C. M. Fan, P. Xue, Y.P, Sun, J. Rare Earths, 24, 309, (2006). 
[35]. L. Bian, M. X. Song, T. L. Zhou, X. Y. Zhou, Q. Q. Dai. J. Rare Earths, 27, 461, (2009).

[36]. M. Zalaj, J. Rare Earths, 32, 487, (2014).

[37]. R. K. Kalaiezhily, V. Asvini, G. Saravanan and K. Ravichandran, Dalton Trans., 48, 12228, (2019).

[38]. J. Iqbal, X. Liu , H. Zhu, Z.B. Wua, Y. Zhang, D. Yu, R. Yu, Acta Mater., 57, 4790, (2009).

[39]. P. Pascariu, M. Homocianu, C. Cojocaru, P. Samoila, A. Airinei, M. Suchea, Appl. Surf. Sci., 476, 16, (2019).

[40]. M. Romero, J. Blanco, B. Sanchez, A. Vidal, S. Malato, A. I. Cardona et. al., Sol. Energy, 66,169, (1999).

[41]. A. Rahman, R. Jayaganthan, Trans. Indian Inst. Met., 70, 1063, (2016).

[42]. C. A. Arguello, D. L. Rousseau, S. P. S. Porto, Phys. Rev., 181, 351, (1969).

[43]. R. Bomila, S. Suresh, S. Srinivasan, J. Mater. Sci: Mater. Electron., 30, 582, (2019).

[44]. X. Z. Li, F. B. Li, C. L. Yang, W. K. Ge, J. Photochem. Photobiol. A, 141, 209, (2009).

[45]. L. Q. Jing, X. J. Sun, W. M. Cai, Z. L. Xu, Y. G. Du, H .G. Fu, J. Phys. Chem. Solid, 64, 615, (2003).

[46]. H. Yamashita, Y. Ichihashi, S. G. Zhang, Y. Matsumurab, Y. Soumab, T. Tatsumic, et al. Appl. Surf. Sci., 121, 305311, (1997).

[47]. R. Bomila, S. Srinivasan, A. Venkatesan, B. Bharath,K. Perinbam, Mater. Res. Innov., 22, 379, (2017).

[48]. X. Liu, D. G, Sroppa, M. Heggan, Y. Ermolenko , A. Offenhausser, Y. Mourzina, J. Phys. Chem. C, 119, 10336, (2015).

[49]. J. H. Zeng, Y. L. Yu, Y. F. Wang, T. Lou, J. Acta. Mater., 57, 1813, (2009). 
[50]. A. George, S. K. Sharma, S. Chawla, M. M. Malik, M. S. Qureshi, J. alloys. Compd., 509, $5942,(2011)$.

[51]. A. Majid, A. Ali, J. Phys. D: Appl. Phys., 42, 45412, (2009).

[52]. K. F. Berggren, B. E. Sernelius, Phys. Rev., 24, 1971, (1981).

[53]. S. Bhatia, N. Verma, Mater. Res. Bull., 95, 468, (2017).

[54]. S. Wang, L. Bai, X. Ao, RSC Adv., 8, 36745, (2018).

[55]. C. J. Chang, C. Y. Lin, M .H .Hsu, J. Taiwan. Inst. Chem. Eng., 45, 1954, (2014).

[56]. R. K. Kalaiezhily, G. Saravanan, V. Asvini, N. Vijayan and K. Ravichandran, Ceram. Int., 44, 19560, (2018).

[57]. R. K. Kalaiezhily, V. Asvini, G. Saravanan and K. Ravichandran, J. Mater. Sci.: Mater. Electron., 29, 12001, (2018).

[58]. R. López and R. Gómez, J. Sol-Gel Sci. Technol., 61, 1, (2012).

[59]. P. Kubelka, J. Opt. Soc. Am., 38, 448, (1948).

\section{$\underline{\text { List of Figures and Table captions }}$}

1) Figure 1(a, b) (a) $\mathrm{XRD}$ pattern of un-doped $\mathrm{ZnO}$ and $\mathrm{La}$, Ce, Dy co-doped $\mathrm{ZnO}$ nanoparticles $\left(\mathrm{Zn}_{0.97} \mathrm{La}_{0.01} \mathrm{Ce}_{0.01} \mathrm{Dy}_{0.01} \mathrm{O}, \mathrm{Zn}_{0.94} \mathrm{La}_{0.02} \mathrm{Ce}_{0.02} \mathrm{Dy}_{0.02} \mathrm{O}\right.$, $\mathrm{Zn}_{0.91} \mathrm{La}_{0.03} \mathrm{Ce}_{0.03} \mathrm{Dy}_{0.03} \mathrm{O}, \quad \mathrm{Zn}_{0.88} \mathrm{La}_{0.04} \mathrm{Ce}_{0.04} \mathrm{Dy}_{0.04} \mathrm{O} \quad \& \quad \mathrm{Zn}_{0.85} \mathrm{La}_{0.05} \mathrm{Ce}_{0.05} \mathrm{Dy}_{0.05} \mathrm{O}$ ) (b) Expanded XRD pattern showing shift towards lower angle with increase in co-dopant concentration.

2) Figure 2(a-f) SEM surface micrographs of un-doped $\mathrm{ZnO}$ and $\mathrm{La}, \mathrm{Ce}$, Dy co-doped $\mathrm{ZnO}$ $\begin{array}{llllll}\text { nanoparticles. } & \text { (a) Un-doped } \quad \mathrm{ZnO}, & \text { (b) } \mathrm{Zn}_{0.97} \mathrm{La}_{0.01} \mathrm{Ce}_{0.01} \mathrm{Dy}_{0.01} \mathrm{O}, \quad \text { (c) }\end{array}$ $\mathrm{Zn}_{0.94} \mathrm{La}_{0.02} \mathrm{Ce}_{0.02} \mathrm{Dy}_{0.02} \mathrm{O}$, (d) $\mathrm{Zn}_{0.91} \mathrm{La}_{0.03} \mathrm{Ce}_{0.03} \mathrm{Dy}_{0.03} \mathrm{O}$, (e) $\mathrm{Zn}_{0.88} \mathrm{La}_{0.04} \mathrm{Ce}_{0.04} \mathrm{Dy}_{0.04} \mathrm{O}$ (f) $\mathrm{Zn}_{0.85} \mathrm{La}_{0.05} \mathrm{Ce}_{0.05} \mathrm{Dy}_{0.05} \mathrm{O}$.

3) Figure 3(a, b) (a) Room temperature PL spectrum of un-doped and La,Ce,Dy co-doped $\mathrm{ZnO} \quad$ nanoparticles $\quad\left(\mathrm{Zn}_{0.97} \mathrm{La}_{0.01} \mathrm{Ce}_{0.01} \mathrm{Dy}_{0.01} \mathrm{O}, \quad \mathrm{Zn}_{0.94} \mathrm{La}_{0.02} \mathrm{Ce}_{0.02} \mathrm{Dy}_{0.02} \mathrm{O}\right.$, $\left.\mathrm{Zn}_{0.91} \mathrm{Laa}_{0.03} \mathrm{Ce}_{0.03} \mathrm{Dy}_{0.03} \mathrm{O}, \quad \mathrm{Zn}_{0.88} \mathrm{La}_{0.04} \mathrm{Ce}_{0.04} \mathrm{Dy}_{0.04} \mathrm{O} \quad \& \quad \mathrm{Zn}_{0.85} \mathrm{La}_{0.05} \mathrm{Ce}_{0.05} \mathrm{Dy}_{0.05} \mathrm{O}\right)$ 
Expanded UV region of the spectrum showing red shift in wavelength with increase in concentration of dopants.

4) Figure 4(a-e) UV-Vis Absorbance spectral changes of Rhodamine B dye solution during photocatalytic degradation with undoped and $\mathrm{La} \mathrm{Ce}$,Dy co-doped $\mathrm{ZnO}$ nanoparticles under UV irradiation at different time intervals. (a) Un-doped $\mathrm{ZnO}$, (b) $\mathrm{Zn}_{0.97} \mathrm{La}_{0.01} \mathrm{Ce}_{0.01} \mathrm{Dy}_{0.01} \mathrm{O}$, (c) $\mathrm{Zn}_{0.94} \mathrm{La}_{0.02} \mathrm{Ce}_{0.02} \mathrm{Dy}_{0.02} \mathrm{O}$, (d) $\mathrm{Zn}_{0.91} \mathrm{Laa}_{0.03} \mathrm{Ce}_{0.03}, \mathrm{Dy}_{0.03} \mathrm{O}$, (e) $\mathrm{Zn}_{0.88} \mathrm{La}_{0.04} \mathrm{Ce}_{0.04} \mathrm{Dy}_{0.04} \mathrm{O} \&$ (f) $\mathrm{Zn}_{0.85} \mathrm{La}_{0.05} \mathrm{Ce}_{0.05} \mathrm{Dy}_{0.05} \mathrm{O}$.

5) Figure 5 (a-c) (a) Photocatalytic degradation of Rhodamine $B$ dye solution un-doped and $\mathrm{La}, \mathrm{Ce}$, Dy co-doped $\mathrm{ZnO}$ nanoparticles

$\left(\mathrm{Zn}_{0.97} \mathrm{La}_{0.01} \mathrm{Ce}_{0.01} \mathrm{Dy}_{0.01} \mathrm{O}, \quad \mathrm{Zn}_{0.94} \mathrm{La}_{0.02} \mathrm{Ce}_{0.02} \mathrm{Dy}_{0.02} \mathrm{O}, \quad \mathrm{Zn}_{0.91} \mathrm{La}_{0.03} \mathrm{Ce}_{0.03} \mathrm{Dy}_{0.03} \mathrm{O}\right.$, $\mathrm{Zn}_{0.88} \mathrm{La}_{0.04} \mathrm{Ce}_{0.04} \mathrm{Dy}_{0.04} \mathrm{O} \& \mathrm{Zn}_{0.85} \mathrm{Laa}_{0.05} \mathrm{Ce}_{0.05} \mathrm{Dy}_{0.05} \mathrm{O}$ ) (b) Reaction kinetics of photo catalytic degradation with un-doped $\mathrm{ZnO}$ nanoparticles and $\mathrm{La}, \mathrm{Ce}$, Dy co-doped $\mathrm{ZnO}$ nanoparticles $\left(\mathrm{Zn}_{0.97} \mathrm{La}_{0.01} \mathrm{Ce}_{0.01} \mathrm{Dy}_{0.01} \mathrm{O}, \quad \mathrm{Zn}_{0.94} \mathrm{La}_{0.02} \mathrm{Ce}_{0.02} \mathrm{Dy}_{0.02} \mathrm{O}, \quad \mathrm{Zn}_{0.91} \mathrm{La}_{0.03} \mathrm{Ce}_{0.03} \mathrm{Dy}_{0.03} \quad \mathrm{O}\right.$, $\left.\mathrm{Zn}_{0.88} \mathrm{La}_{0.04} \mathrm{Ce}_{0.04} \mathrm{Dy}_{0.04} \mathrm{O} \& \mathrm{Zn}_{0.85} \mathrm{La}_{0.05} \mathrm{Ce}_{0.05} \mathrm{Dy}_{0.05} \mathrm{O}\right) \quad$ under $\mathrm{UV}$ irradiation at different time intervals.

(c) Photocatalytic degradation precentage of Rhodamine $\mathrm{B}$ dye solution with undoped $\mathrm{ZnO}$ and $\mathrm{La}, \mathrm{Ce}, \quad \mathrm{Dy}$ co-doped $\mathrm{ZnO}$ nanoparticles $\left(\mathrm{Zn}_{0.97} \mathrm{La}_{0.01} \mathrm{Ce}_{0.01} \mathrm{Dy}_{0.01} \mathrm{O}\right.$, $\mathrm{Zn}_{0.94} \mathrm{La}_{0.02} \mathrm{Ce}_{0.02} \mathrm{Dy}_{0.02} \mathrm{O}, \quad \mathrm{Zn}_{0.91} \mathrm{La}_{0.03} \mathrm{Ce}_{0.03} \mathrm{Dy}_{0.03} \mathrm{O}, \quad \mathrm{Zn}_{0.88} \mathrm{La}_{0.04} \mathrm{Ce}_{0.04} \mathrm{Dy}_{0.04} \mathrm{O} \quad \&$ $\left.\mathrm{Zn}_{0.85} \mathrm{La}_{0.05} \mathrm{Ce}_{0.05} \mathrm{Dy}_{0.05} \mathrm{O}\right)$ under UV irradiation at different time intervals.

6) Fig 6(a, b) (a) Reflectance spectra of un-doped and $\mathrm{Zn}_{0.97} \mathrm{Laa}_{0.01} \mathrm{Ce}_{0.01}, \mathrm{Dy}_{0.01} \mathrm{OZn}_{0.91} \mathrm{La}_{0.03} \mathrm{Ce}_{0.03} \mathrm{Dy}_{0.03} \mathrm{O}$, \& $\mathrm{Zn}_{0.85} \mathrm{La}_{0.05} \mathrm{Ce}_{0.05} \mathrm{Dy}_{0.05} \mathrm{O}$ (b) Bandgap plot using the Kubelka-Munk function.

7) Table 1 Standard conditions for synthesis of $\mathrm{La}, \mathrm{Ce}$, Dy co-doped $\mathrm{ZnO}$ nanoparticles $\mathrm{x}=(0.00-0.05)$

8) Table 2 Calculated lattice parameters and crystallite size of undoped and $\mathrm{La}, \mathrm{Ce}, \mathrm{Dy}$ codoped $\mathrm{ZnO}$ nanoparticles 
Figures
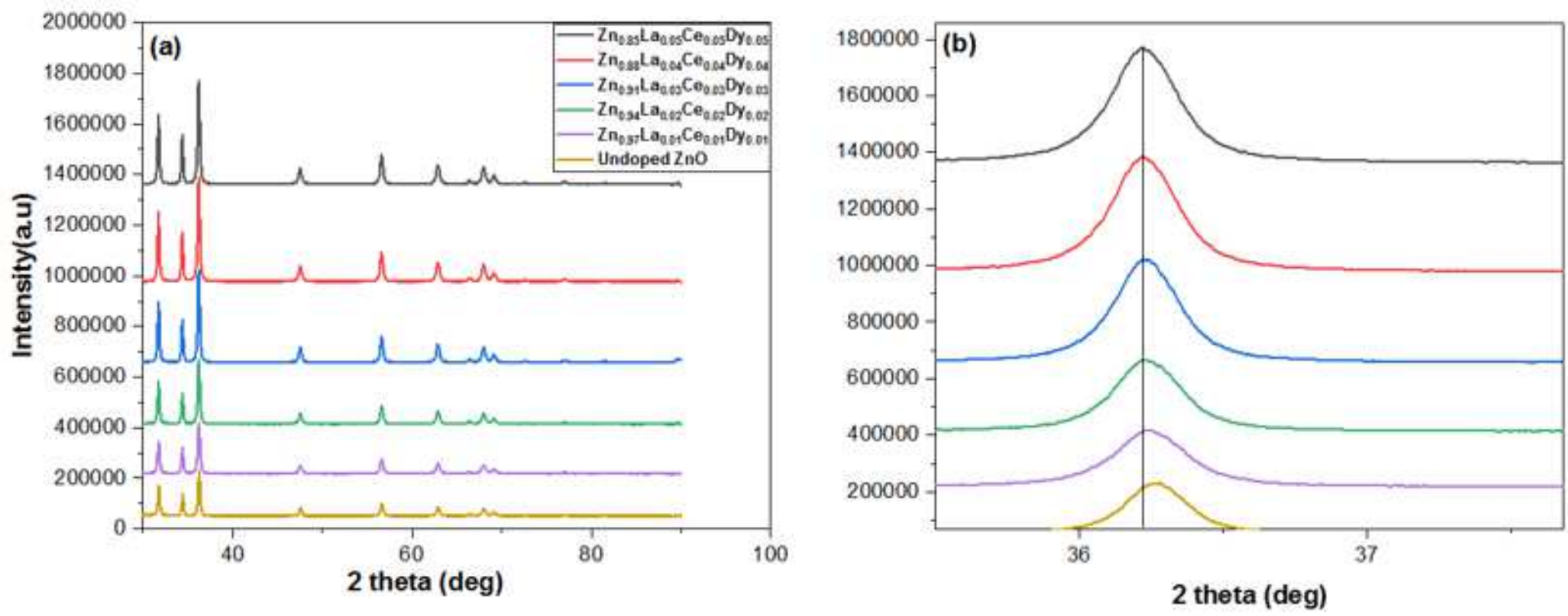

\section{Figure 1}

(a, b) (a) XRD pattern of un-doped ZnO and La, Ce, Dy co-doped ZnO nanoparticles (Zn0.97La0.01Ce0.01Dy0.010, Zn0.94La0.02Ce0.02Dy0.020, Zn0.91La0.03Ce0.03Dy0.030, Zn0.88La0.04Ce0.04Dy0.040 \& Zn0.85La0.05Ce0.05Dy0.050) (b) Expanded XRD pattern showing shift towards lower angle with increase in co-dopant concentration. 

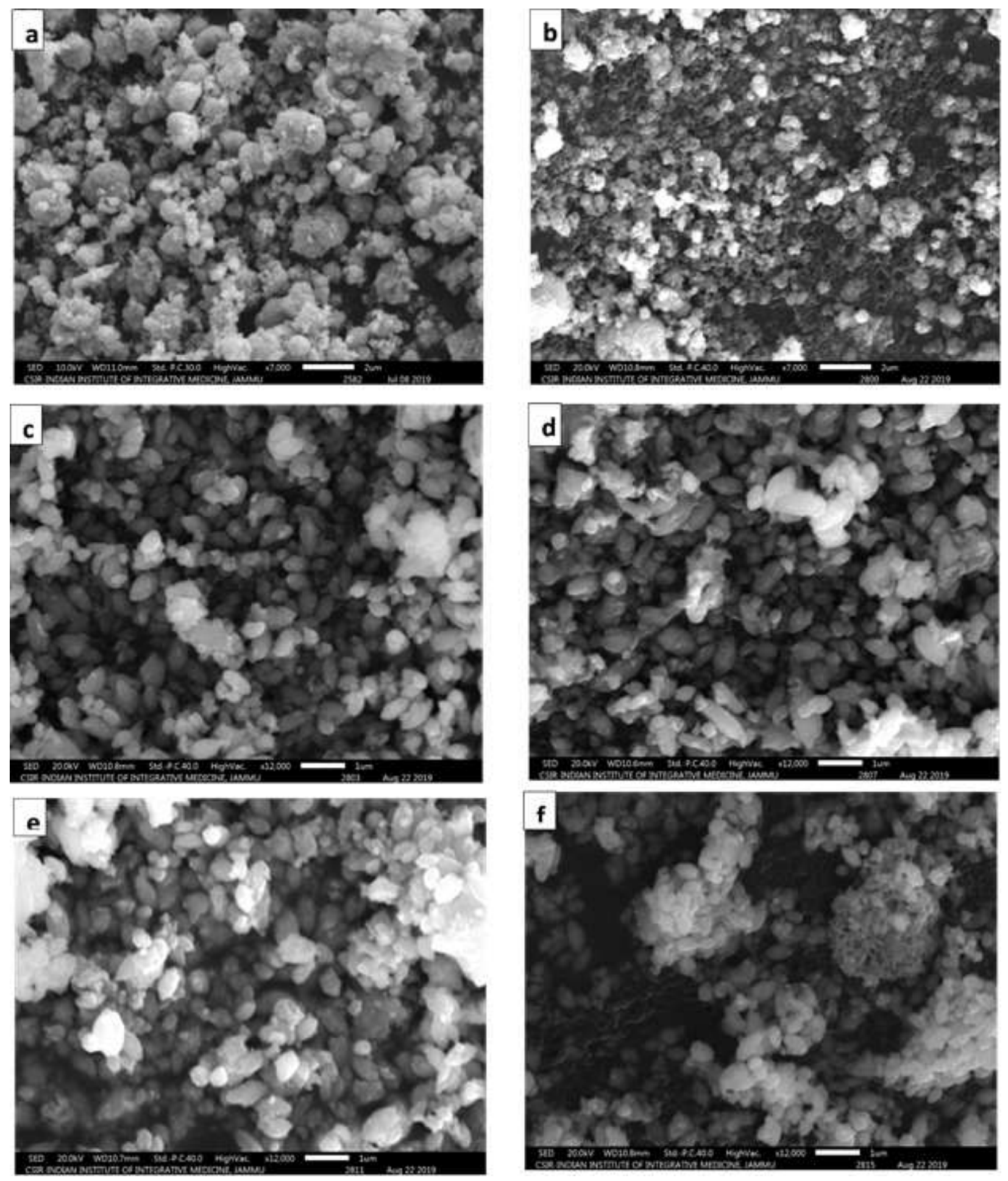

Figure 2

(a-f) SEM surface micrographs of un-doped $\mathrm{ZnO}$ and $\mathrm{La}$, Ce, Dy co-doped $\mathrm{ZnO}$ nanoparticles. (a) Undoped ZnO, (b) Zn0.97La0.01Ce0.01Dy0.010, (c) Zn0.94La0.02Ce0.02Dy0.02O, (d) Zn0.91La0.03Ce0.03Dy0.030, (e) Zn0.88La0.04Ce0.04Dy0.040 (f) Zn0.85La0.05Ce0.05Dy0.050. 

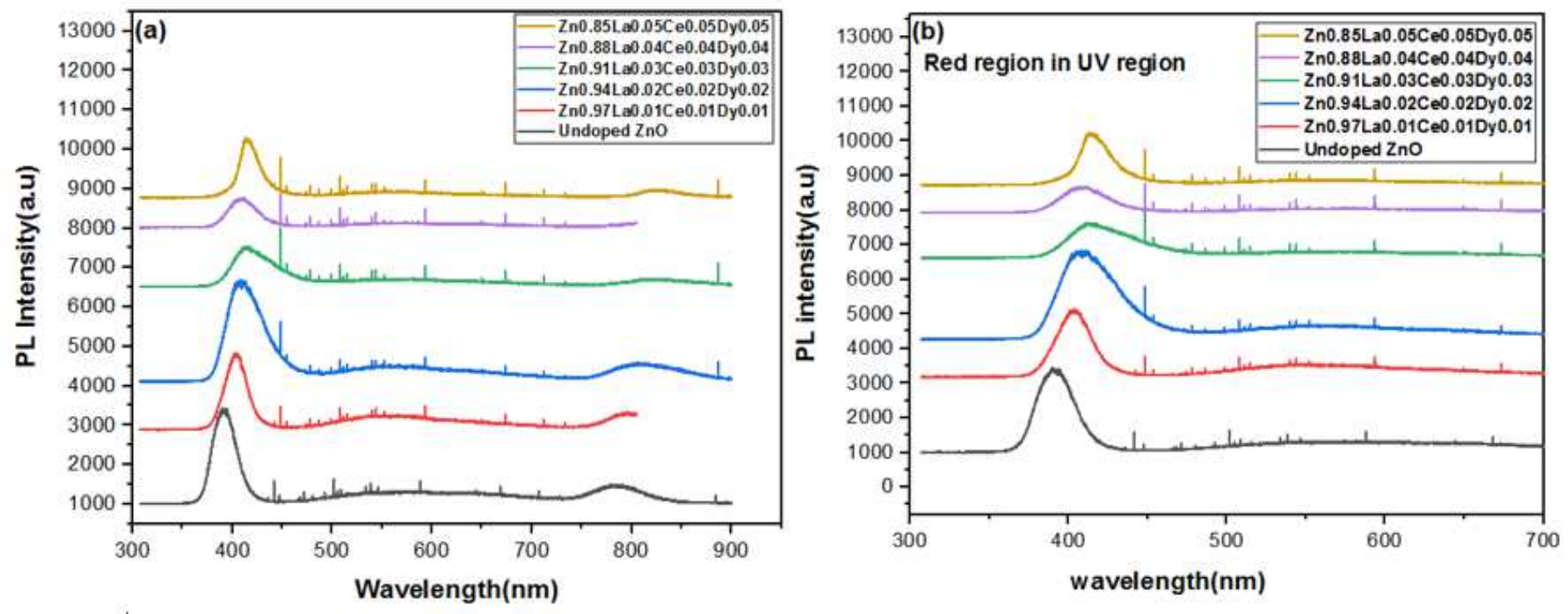

Figure 3

(a, b) (a) Room temperature PL spectrum of un-doped and La,Ce,Dy co-doped ZnO nanoparticles (Zn0.97La0.01Ce0.01Dy0.010, Zn0.94La0.02Ce0.02Dy0.02O, Zn0.91La0.03Ce0.03Dy0.030, Zn0.88La0.04Ce0.04Dy0.040 \& Zn0.85La0.05Ce0.05Dy0.050) (b) Expanded UV region of the spectrum showing red shift in wavelength with increase in concentration of dopants. 

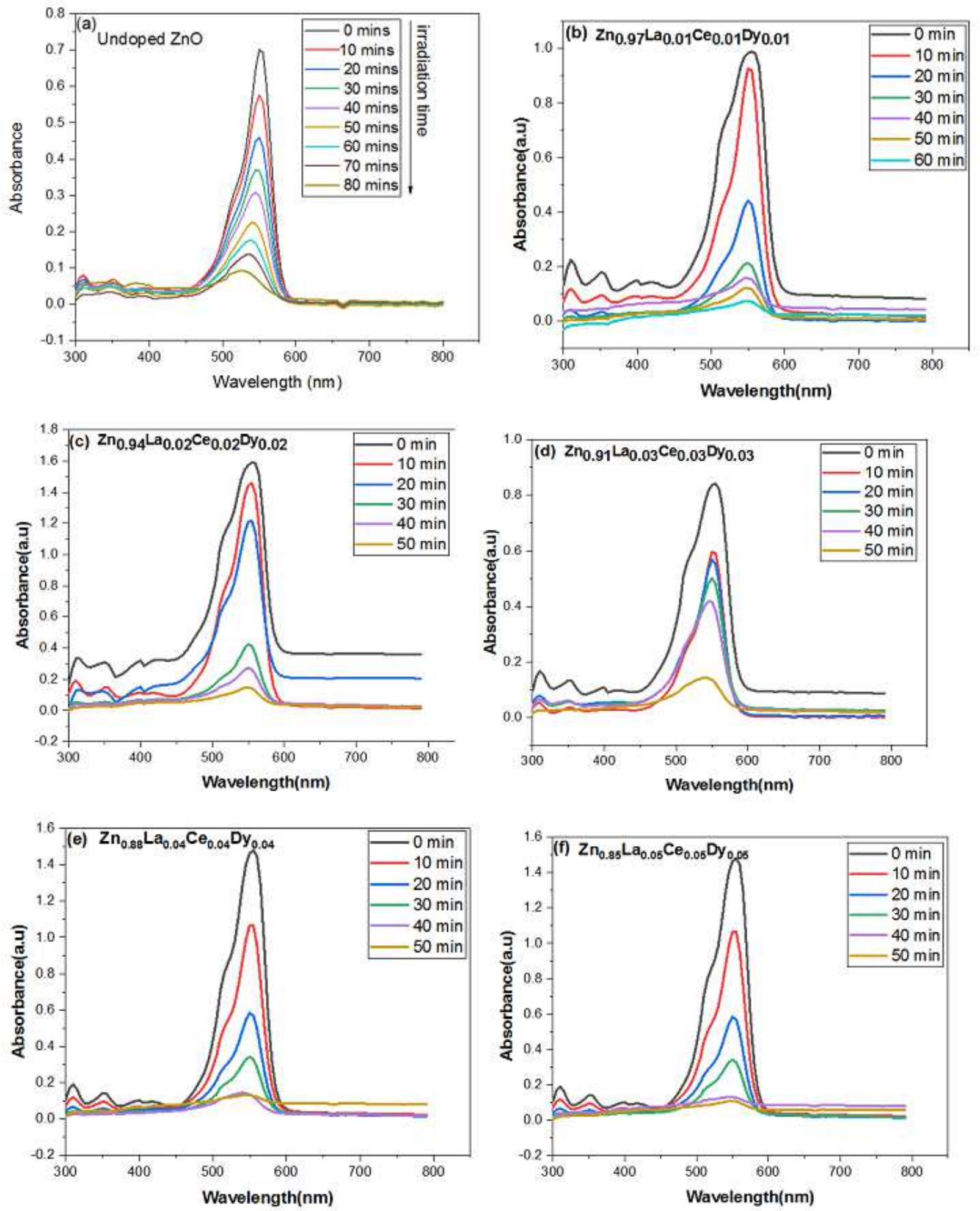

\section{Figure 4}

(a-e) UV-Vis Absorbance spectral changes of Rhodamine B dye solution during photocatalytic degradation with undoped and La Ce,Dy co-doped ZnO nanoparticles under UV irradiation at different time intervals. (a) Un-doped ZnO, (b) Zn0.97La0.01Ce0.01Dy0.010, (c) Zn0.94La0.02Ce0.02Dy0.02O, (d) Zn0.91La0.03Ce0.03,Dy0.030, (e) Zn0.88La0.04Ce0.04Dy0.040 \& (f) Zn0.85La0.05Ce0.05Dy0.050. 

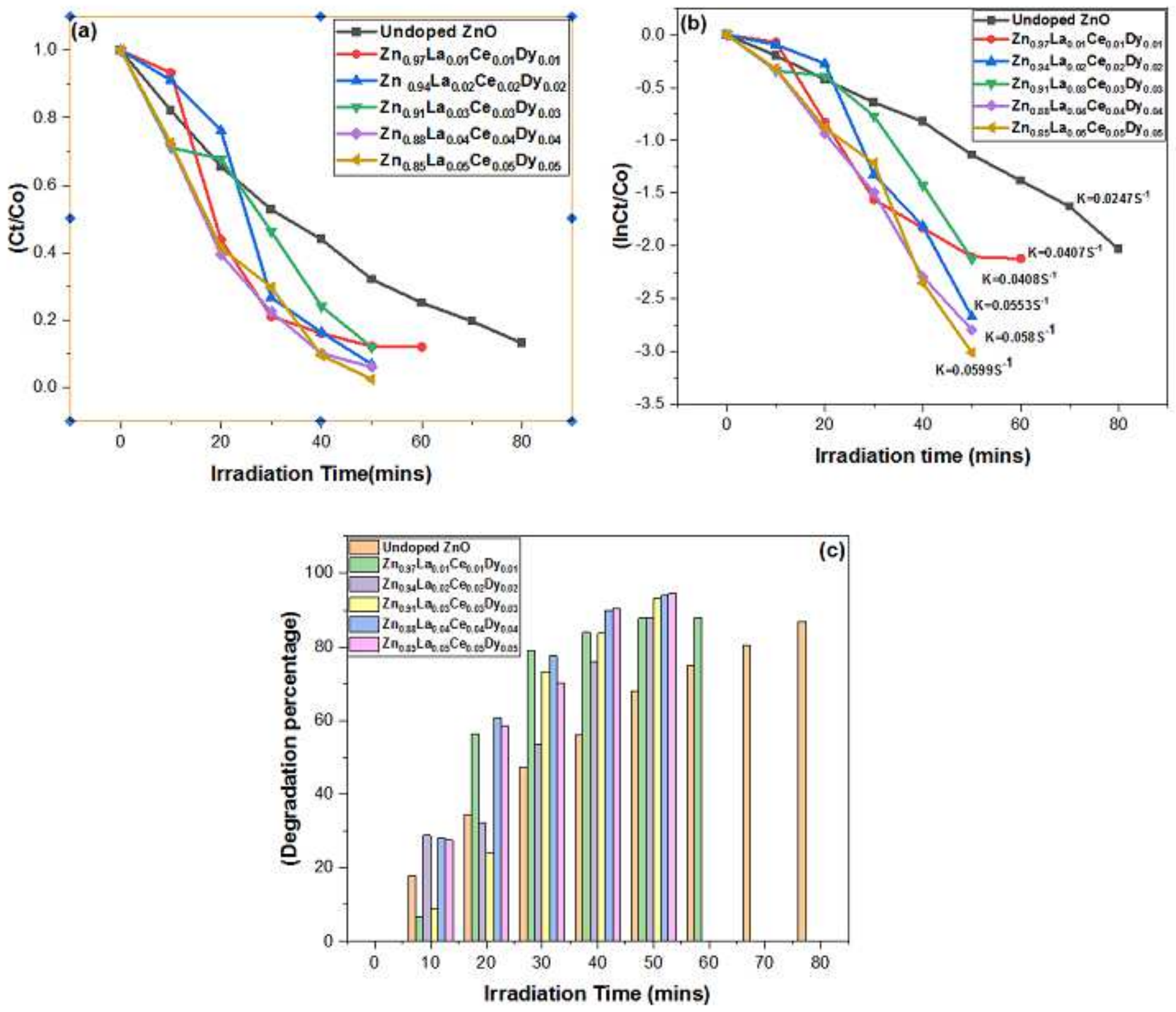

Figure 5

(a-c) (a) Photocatalytic degradation of Rhodamine B dye solution un-doped and $\mathrm{La}$, Ce, Dy co-doped ZnO nanoparticles (Zn0.97La0.01Ce0.01Dy0.010, Zn0.94La0.02Ce0.02Dy0.02O, Zn0.91La0.03Ce0.03Dy0.030, Zn0.88La0.04Ce0.04Dy0.040 \& Zn0.85La0.05Ce0.05Dy0.050) (b) Reaction kinetics of photo catalytic degradation with un-doped $\mathrm{ZnO}$ nanoparticles and La, Ce, Dy codoped ZnO nanoparticles (Zn0.97La0.01Ce0.01Dy0.010, Zn0.94La0.02Ce0.02Dy0.020, Zn0.91La0.03Ce0.03Dy0.03 0, Zn0.88La0.04Ce0.04Dy0.040 \& Zn0.85La0.05Ce0.05Dy0.050) under UV irradiation at different time intervals. (c) Photocatalytic degradation precentage of Rhodamine $B$ dye solution with undoped $\mathrm{ZnO}$ and $\mathrm{La}$, Ce, Dy co-doped ZnO nanoparticles (Zn0.97La0.01Ce0.01Dy0.010, Zn0.94La0.02Ce0.02Dy0.020, Zn0.91La0.03Ce0.03Dy0.030, Zn0.88La0.04Ce0.04Dy0.040 \&

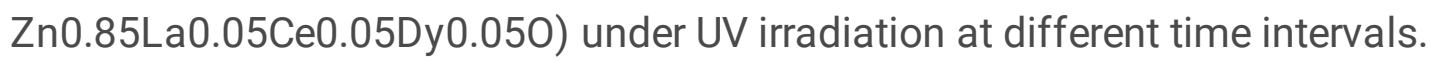



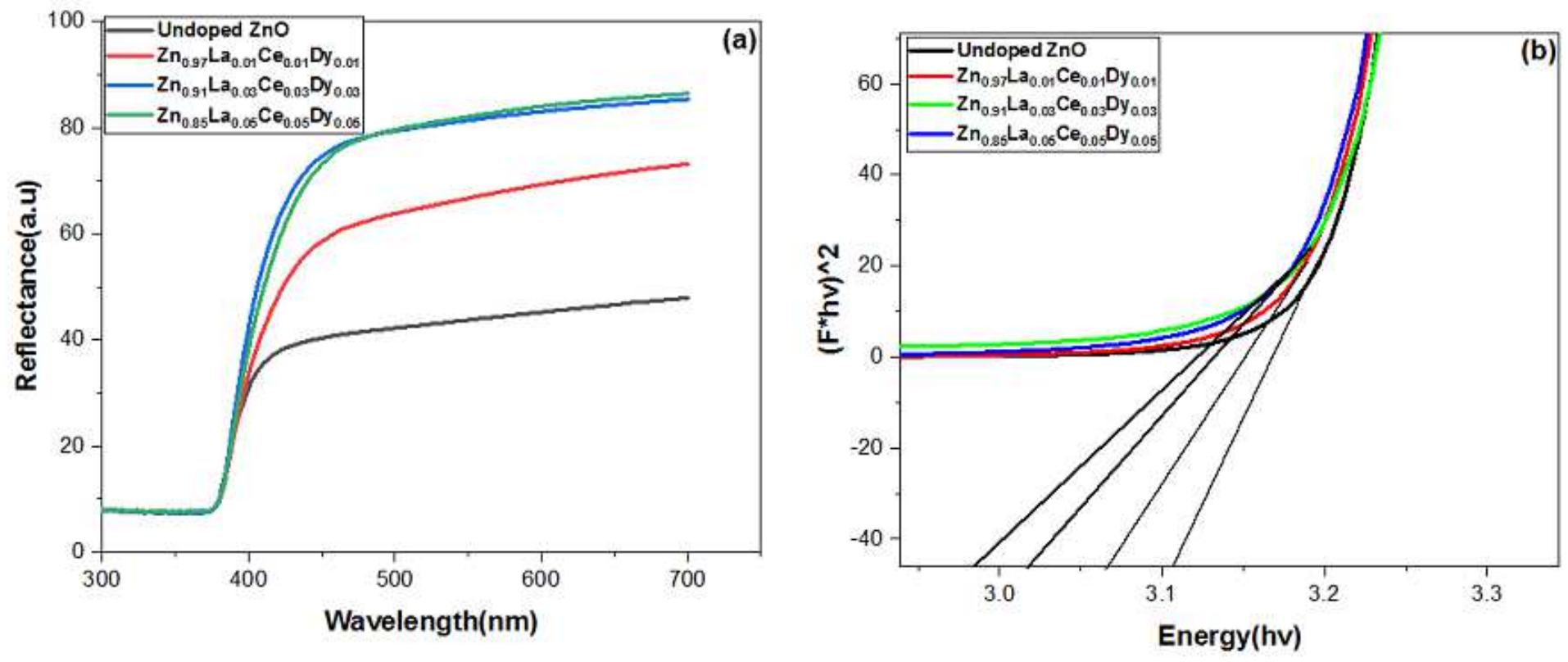

Figure 6

$(a, b)(a)$ Reflectance spectra of un-doped and Zn0.97La0.01Ce0.01,Dy0.010Zn0.91La0.03Ce0.03Dy0.030, \& Zn0.85La0.05Ce0.05Dy0.050 (b) Bandgap plot using the Kubelka-Munk function.

\section{Supplementary Files}

This is a list of supplementary files associated with this preprint. Click to download.

- Table1.docx

- Table2.docx 